\title{
DO PLURALISMO JURÍDICO JUDICIAL OFICIAL ATRAVÉS DA TÓPICA E DA POÉTICA - A LIBERTAÇÃO NORMATIVA PELA SENSIBILIDADE SOCIAL CRÍTICA DO JUIZ
}

\section{${ }^{1}$ Danilo Fontenele Sampaio Cunha}

\section{RESUMO}

O pluralismo jurídico é entendido como forma de acesso à justiça através de instâncias de decisão além da estatal e utilização de fontes normativas diversas das oficiais. Propomos que os juízes sejam incentivados a interpretarem, redefinirem e aplicarem as normas conforme o contexto social, econômico, político e cultural, através da retomada da tópica e da poética. Nesta perspectiva cremos poder ser alcançada a emancipação normativa pela sensibilidade social crítica, permitindo a descolonização do futuro através da constante conversão à democracia solidária, mediante a prevalência do humanismo reinterpretado pelas atuações de seus julgadores, no que chamamos de pluralismo jurídico judicial oficial

Palavras-chave: Pluralismo jurídico, Tópica, Poética

\section{DEL PLURALISMO JURÍDICO JUDICIAL A TRAVÉS DE LA TÓPICA Y DE LA POÉTICA - LA LIBERACIÓN NORMATIVA A TRAVÉS DE LA SENSIBILIDAD SOCIAL CRÍTICA DEL JUEZ}

\section{RESUMEN}

El pluralismo jurídico es entendido como forma de accederse la justicia a través de decisiónes además de la estatal y utilización de fuentes normativas diversas de las oficiales. Proponemos que los jueces apliquen las normas conforme el contexto social a través de la renudación de la tópica y de la poética. Creemos poder ser alcanzada la emancipação normativa por la sensibilidad social crítica, permitiendo la descolonização del futuro a través de la constante conversión a la democracia solidaria, con la prevalência del humanismo a través de las actuaciones de sus julgadores, en el que llamamos de pluralismo jurídico judicial oficial.

Palabras-claves: Pluralismo jurídico, Tópica, Poética

\footnotetext{
1 Doutor em Direito pela Pontifícia Universidade Católica de São Paulo - PUC/SP, São Paulo. (Brasil). Diretor do Foro do Justiça Federal do Ceará, Ceará. (Brasil). E-mail: daniloffc@uol.com.br
} 


\section{INTRODUÇÃO}

As diversificações das relações interpessoais e o significativo aumento dos conflitos sociais, com a correspondente multiplicação do número de demandas judiciais e extrajudiciais, fazem com que o tema pluralismo jurídico continue a deter atenção especial dos Estados de Direito que se identificam com a democracia.

A conceituação do que seja pluralismo jurídico sofreu mutações ao longo do tempo em franca identidade complexa, desenvolvendo perspectivas e profundidades que se cruzam, interpenetram e variam conforme os tempos, regimes políticos e conformações sociais, sugerindo que respostas definitivas sobre seus matizes continuem inconclusivas.

A inicial dificuldade é percebida ante a abrangência do assunto, vez que qualquer tentativa de definição única revela-se condenada a resultados insatisfatórios, bem como o termo pode ser compreendido de forma mais ou menos ampla.

Pretendemos, pois, apresentar uma nova perspectiva de pluralismo jurídico oriunda das múltiplas interações sociais que favorecem o ideal de uma justiça cada vez mais comunitariamente sensível.

Para tanto, escolhemos rota diversa das usuais ao não percorrermos as mesmas sendas de se pregar um pluralismo jurídico fora dos contornos estatais.

Aqui, acolhemos e estimulamos que o próprio Estado utilize, em suas manifestações decisórias oficiais e através das leis e normas substantivas e processuais postas, bem como por intermédio de seus órgãos e agentes oficiais, o sentido do justo aferido conforme a tópica e a poética de cada caso.

O pluralismo jurídico aqui tratado é, pois, unido à justiça estatal institucionalizada, o que favorece ampla abertura à busca da configuração cada vez mais sensível e democrática da interpretação e aplicação das normas, de acordo com as densidades humanas dos processos.

Assim o fazemos tendo em vista que o princípio estrutural característico dos ordenamentos jurídicos democráticos indica a submissão de todos, incluindo a administração pública, à Constituição, além de contarmos com a percepção de que a democracia e a liberdade só são densamente estabelecidas quando o Direito humanamente comprometido surge concreta e faticamente nas decisões dos magistrados, operando estas como instrumentos críticos que dão forma à emancipação pessoal e social.

Cremos, pois, que se é verdade que cabe ao Direito boa parte do estabelecimento das condições existenciais da sociedade democrática e ao Poder Judiciário o monopólio último da interpretação e aplicação final e coercitivo do sistema de normas, há que desenvolver-se constante processo de legitimação.

O que aqui propormos e incentivamos é que os julgadores oficiais, ao priorizarem as questões ético-social de conformação efetivamente prática, superem os obstáculos de caráter 
material, processual e simbólico que limitam o acesso à verdadeira liberdade, operando, em cada caso, novas concepções do aplicável, sempre democráticas e republicanas, ampliando e aplicando topicamente a poética da justiça, com larga margem à efetivação dos direitos sociais, civis e políticos em suas amplitudes e potências, diminuindo-se as disfunções existentes.

Neste cenário, a estruturação da presente tese parte, em termos gerais, da transição paradigmática da atuação estatal, agora baseada no diálogo empático e na superação dos paradoxos e riscos éticos atuais, exercitando sua constante conversão à democracia solidária mediante constante processo de sensibilização ativa e correspondente legitimação social.

Ao final pretendemos apresentar uma compreensão em torno das expectativas sobre a ação de decidir e formas possíveis dos comportamentos esperados dos magistrados.

\section{DO PLURALISMO JURÍDICO EXTERNO AO OFICIAL INTERNO - DA SOLIDÃO NORMATIVA À SOLIDARIEDADE HUMANA}

É comum a percepção dos vários componentes práticos do acesso à Justiça estatal e seus correspondentes e contraditórios obstáculos sistêmicos, sendo as emanações oficiais problematizadas a tal ponto que é comum concluir ser o apelo a fontes outras e instâncias diversas das oficiais, a solução possível para melhor se densificar a cidadania, aceitando-se falar da existência do que se pode chamar de pluralismo jurídico, na percepção de normatividades diversas das postas e admissão de fontes decisórias exteriores ao sistema jurídico estatal.

Assim, as conhecidas peculiaridades e limitações dos modos de acesso técnico, rituais, formas e linguagem aplicados, o tempo e prazo para tanto, os simbolismos, cenários e formas de interação, trazem a aceitação de que tais aspectos burocráticos são insuficientes à real compreensão do que verdadeiramente significa acesso à Justiça, ante o distanciamento estatal das realidades humanamente complexas, sugerindo-se a adoção de fontes jurídicas e órgãos judiciais externos à administração pública.

\subsection{O pluralismo jurídico como expressão da necessidade de justiça.}

A percepção do pluralismo jurídico parte da verificação de que qualquer tentativa de definição única do Direito ou Justiça revela-se condenada a resultados insatisfatórios.

A imagem inicial de identificação das expressões Direito e Justiça com regras ou normas legais ou atuação exclusiva do Estado, na dicção do que seja aplicável, exigível e 
coercível diante da necessidade de resolução de lides, mostra-se, segundo tal entendimento, redutora, incompleta e mesmo tímida.

Dizemos redutora por não reconhecer outras instâncias legitimadas para tal resolução que não os órgãos estatais. Incompleta, vez que identifica o Estado como única fonte de produção das normas aplicáveis. E tímida, por não atinar para as estruturas socioeconômicas que conduziram a pretensão ou a resistência.

Ressaltemos ainda que o multiculturalismo próprio de países com várias identidades e influências culturais, ou decorrentes dos contatos culturais e das difusões de informações, também podem ensejar o pluralismo jurídico.

Surge este, pois, como alternativa à jurisdição estatal e contribui para compreender-se o acesso ao Direito e à Justiça como fenômeno complexo e multifacetado.

Observemos, contudo, que apesar da chamada globalização das técnicas, da política e do mercado e o pluralismo jurídico estarem, por assim dizer, em moda nas discussões acadêmicas, tais fenômenos são antigos e acompanharam a expansão das nações.

$\mathrm{Na}$ verdade era comum na sociedade europeia medieval a convivência de diversas ordens jurídicas como o direito romano, o direito canônico, direitos locais, direitos das profissões, estatutos diversos e relativos ao sexo e idade, as dos subordinados e da nobreza, regras de sucessões e patrimônio, regramentos políticos e uma série de soluções particulares e casuísticas.

Podemos entender, portanto, por pluralismo jurídico justamente a coexistência de ordens normativas e decisórias vigentes, cogentes e exigíveis do ponto de vista prático de regulação social no local e no tempo da comunidade em que se inserem.

Desta feita, é possível asseverarmos que em todo processo de colonização sempre existiu tal multiplicidade de maneiras de resolução de conflitos. Assim, normalmente nas sociedades coloniais, o direito europeu era empregado nas questões envolvendo colonizadorcolonizado e os direitos dos povos nativos continuavam regendo as relações locais entre os naturais.

Em tempos mais recentes o pluralismo jurídico também foi aplicado no colonialismo europeu, mormente no período de entre as duas guerras. Assim, a Inglaterra, Holanda e a França administravam suas colônias baseadas no autogoverno (self rule) que permitia que os nativos regulassem suas relações por suas próprias instituições e através de seu direito, mas debaixo de certa supervisão da potência colonial ${ }^{1}$.

${ }^{1}$ HESPANHA, António Manuel, Cultura Jurídica Européia - síntese de um milênio, Sintra: Publicações EuropaAmérica, $3^{\mathrm{a}}$ edição, 2003, p.116 e 356. 
Ademais, pode-se falar em pluralismo jurídico tanto como forma de se acessar a justiça pela procura de instâncias de decisão além da estatal, da mesma maneira que se pode entender como a possibilidade de utilização de fontes normativas diversas da oficial.

Frise-se que é possível afirmarmos, mesmo com grande dose de generalização, que tal procura por normas, meios e instâncias distintos das legais ocorre pelo fato do Estado não conseguir se fazer presente em certas ocasiões de conflito ou para determinados grupos, não os alcançando, contemplando ou protegendo de forma sensivelmente aceitável, ou em palavras mais simples: o pluralismo existe porque é necessário existir.

Apresenta-se, portanto, o pluralismo jurídico, no que pese o tema ou sua própria definição não serem pacíficos nos círculos acadêmicos ${ }^{2}$, como sendo um conjunto de ordens normativas e decisórias que coexistem e se interligam, quer sejam reconhecidas ou não pelo Estado.

Assim, por exemplo, podemos entender o pluralismo jurídico diante dos ordenamentos e regimes jurídicos locais, nacionais e transnacionais materializados em acordos, tratados, convenções, declarações e protocolos com efeitos jurídicos, nas ordens normativas das comunidades indígenas, dos presidiários, das comunidades de assentamentos rurais, no conjunto de normas existentes nas comunidades dos morros cariocas brasileiros, nas normas do direito canônico e mesmo nos programas, guias, indicadores e linhas de orientação elaboradas pelas agências de regulação, quer sejam encaradas como principal fonte do direito, superando o direito estatal, ou derivadas como categoria dos costumes ou necessidades sociais atuais.

Afirmamos, portanto, a coexistência de diversas ordens normativas com a ordem normativa estatal, sem necessariamente serem mutuamente exclusivas, contando com vários pontos de contato, associações, sobreposições e interpenetrações, nas diversas situações e contextos.

$\mathrm{Na}$ verdade, todas as formas de Justiça, sejam as criadas e desenvolvidas formalmente pelo Estado ou iniciadas por necessidade popular, como as implementadas por instâncias tradicionais ou religiosas, ou mesmo as incentivadas por Organizações Não Governamentais, identificam-se com a resolução de conflitos, no que pese suas formas de atuação poderem ser mais ou menos rígidas em relação à adoção dos procedimentos e normas estatais ou mesmo realizar-se alguma forma de simbiose entre estas e as normas comunitárias.

\footnotetext{
${ }^{2}$ Ver SANTOS, Boaventura de Sousa e TRINDADE, João Carlos (org.), Conflito e Transformação social: uma paisagem das justiças em Moçambique, Vol.I, Porto: Afrontamento, 2003, pp.47-128.
} 
O certo é que a solução dos conflitos não está limitada pela normatividade posta. Sua adoção enseja apenas a preservação das relações sociais vivenciadas conforme os valores de uma época e por determinado povo em sua região, mas é cediço que a dinâmica social é mais célere que a correspondente adaptação normativa.

Admitimos, ainda, que as normas sociais seguidas por uma comunidade possam ser diferentes de outros regulamentos de grupos de distintas localidades, no que pese fazerem parte de um mesmo Estado, malgrado tais constatações serem mais comuns em países de larga extensão territorial, amplas zonas de fronteiras ou caracterizados pela presença de forte multiculturalismo.

Ressaltemos que tal diversidade é originada pelas várias bases valorativas e não apenas por substratos normativos distintos. Na verdade, os valores preenchem e dão sentido às ações e, assim, tanto os comportamentos quanto as instituições apoiam-se em valores e, estas, ao atuar, os (re) criam, fortalecendo-os e confirmando-os, complementando-os e estendendo-os, enfraquecendo-os ou revisando-os.

O cumprimento das normas oficiais pode, pois, ser exigido, incentivado ou favorecido. E tal pode ocorrer de diversas maneiras tais como dentro, fora e além, de maneira lateral e de forma contrária à regulação estatal.

Assim, ocorre o cumprimento normativo dentro do sistema formal como decorrente das atividades estatais judiciais típicas.

O cumprimento das normas pode dar-se fora e além de tal sistema estatal como nas hipóteses de adoção dos tratados e convenções internacionais e as normas resultantes da União Européia.

$\mathrm{O}$ mesmo fenômeno pode também ocorrer de maneira lateral, como as experiências de resolução alternativa de litígios como a mediação, arbitragem, sistemas de defesa de consumidores e negociações oficiais ou não, além do reconhecimento ${ }^{3}$ de sistemas de organização social e regulação de atividades diversos ou complementares ${ }^{4}$, mas contemporâneos e paralelos ao exclusivamente estatal.

Também pode dar-se em contrário e apesar das atividades estatais, como nas hipóteses de regulação normativa de organizações criminosas.

Apresenta-se, consequentemente, o pluralismo jurídico como sistemas de regulação e práticas de deliberação socialmente valorizadas, aí englobando a normatividade oficial e a social, bem como as instâncias estatais e populares.

Observemos, no entanto, que a mera tradição não garante justiça, vez que aquela pode refletir preconceitos, assimetrias e diferenças, ou favorecer o poder das elites locais e perpetuar padrões de influência informal em prejuízo da igualdade ${ }^{5}$ e da liberdade.

Frisemos que pode o pluralismo jurídico também ser apenas suportado ante a ausência de alternativas, como no que diz respeito às práticas mafiosas e os sistemas internos de regulação das relações nos presídios. 
O pluralismo jurídico pode coexistir, pois, concomitante com o pluralismo social e político, admitindo-se formas híbridas de pluralismo jurídico, como o pluralismo interno oficial a seguir proposto.

${ }^{3}$ A Constituição Federal brasileira de 1988 reconheceu aos índios, no art. 231, sua organização social, costumes, línguas, crenças e tradições. Não há, pois, como negar que o Direito está inserido na organização social dos povos indígenas. Neste aspecto, observe-se que a Convenção no 169 da Organização Internacional do TrabalhoOIT sobre povos indígenas e tribais, ratificada pelo Brasil através do Decreto nº 5.051, de 19 de abril de 2004.

${ }^{4}$ Sabe-se que a ideia de propriedade constitui-se verdadeira mentalidade a orientar os comportamentos e representar a estrutura com que historicamente rege a civilização, principalmente a ocidental. No entanto, a feição clássica de propriedade reconhecida e normatizada exclusivamente pelo Estado já convive com outras modalidades mais amplas, que admitem regulação compartilhada com a comunidade, com o resgate do interesse coletivo como parâmetro de equilíbrio. Assim, podemos indicar com base no estudo do Professor José Casalta Nabais, os baldios em Portugal (art. 82, n.4, alínea $c$ da Constituição Portuguesa e Lei n. 68/93, Acórdãos n. 325/89 e 240/91), os bienes comunales em Espanha (art. 132, n.1 da Constituição da Espanha, Lei n.55/80, Ley de Bases Del Régimen Local de 1985 e Regulamento de Bienes de 1986, sobre o aproveitamento dos terrenos e montes vincinais pela comunidade), os biens seccionaux em França (Lei 85-30 de 1985), e os Beni ou demani civici, beni ou deman icolletivi, comunanze, partecipanze, consorterie em Itália (Lei n. 1766 de 1927). NABAIS, José Casalta, Alguns perfis da propriedade colectiva nos países do civil Law. Estudos em Homenagem ao Professor Doutor Rogério Santos. Boletim da Faculdade de Direito da Universidade de Coimbra, Coimbra n. 61, 2001 (p.224-251), p.224. No Brasil algumas hipóteses de regulação conjunta da propriedade podem ser citadas, como as terras indígenas e os remanescentes das comunidades dos quilombos (art. 20, XI c/c art. 231 da Constituição Federal e art. 68 do Ato das Disposições Constitucionais Transitórias), as terras públicas e devolutas para reforma agrária (art. 189 da Constituição Federal), as regulamentações da utilização de áreas de uso comum, como matas para coleta de frutos, castanhas, cipós, e caça de subsistência nas Reservas Extrativistas (Código Florestal - Lei 4.771/65), áreas reguladas pela Lei de Gestão de Florestas (Lei n. 11.284/2006), pela Lei das Unidades de Conservação e regulações das atividades extrativistas (Lei n. 9985/2000), e pelo Decreto $n$. 6040, de 2007, que institui a política nacional de desenvolvimento sustentável dos povos e comunidades tradicionais. É certo que os modos de vida da terra comum, com as características do criar, fazer e viver são considerados patrimônio cultural (art. 216, II da Constituição Federal). São exemplos as formas de vida das comunidades tradicionais dos sertanejos, seringueiros, quilombolas, agroextrativistas da Amazônia, pescadores artesanais, povos de terreiro (comunidade Bantu), ciganos, indígenas, pantaneiros e caiçaras.

${ }^{5}$ Neste aspecto esclarece Kwame Anthony Appiah que a diversidade não possui um valor intrínseco, existindo diversidades terríveis que devem ser objetáveis. APPIAH, Kwame Anthony, Mi Cosmopolismo - entrevista com Daniel Gamper Sachse, sem indicação de título original, tradução de Lilia Mosconi, Barcelona: Katz Editores e Centro de Cultura Contemporánea de Barcelona, 2008, pp.49 e 53. 


\subsection{Da possibilidade de pluralismo jurídico oficial interno.}

Podemos afirmar que o acesso ao Direito e à Justiça vai além do exame da origem das normas, e acarreta a verificação do conteúdo destas na aplicação particular específica no caso concreto, na dupla perspectiva de produção legislativa e produção decisória, podendo estas serem estatais ou não.

Ressaltemos, pois, que dito o pluralismo jurídico pode ser também verificado no que se refere à sua realização, aqui entendido como aplicação e efetividade social da concretização da norma no plano real, ou seja, no trânsito da dimensão ideal da regulação para a densificação social pertinente.

Daí advém as verificações de conformidade e adequação das normas e de sua aplicação com os ideais de igualdade política e social, em uma ambiência justa, responsável e equitativa na distribuição das conquistas sociais, cabendo a adoção de estratégias hermenêuticas capazes de assegurar simultaneamente a liberdade e ampliar a igualdade, permitindo a conformação do sistema normativo à realidade socioeconômica.

Agindo desta maneira as regras de julgamento, normas e conceitos jurídicos podem ser interpretados e redefinidos conforme o contexto social, econômico, político e cultural, balanceando-se os direitos e as obrigações no sistema social, ao mesmo tempo em que propiciam julgamentos socialmente equilibrados, sem que isso signifique arbítrio ou anomia jurídica.

Identificamos, assim, como primeira expressão do que chamamos de pluralismo jurídico interno as manifestações oficiais da Justiça que utilizam formas, meios e métodos de resolução informais ao invés dos critérios exclusivamente legais, como em diversas experiências por meio dos juizados especiais brasileiros, que possuem espectro mais abrangente que a mera interpretação extensiva.

No entanto cremos que mesmo nos casos de procedibilidade regular, ante a multiplicidade de episódios cada vez mais complexos e multifacetados, o magistrado é sempre chamado a interpretar os fatos em conjunto com a decodificação das pessoas envolvidas nos mesmos.

Assim, é o juiz convocado a indagar, observar e avaliar nos protagonistas da questão, suas intenções, desejos, interesses, anseios e mesmo valores como forma de assegurar uma aproximação da versão mais precisa do que ocorreu e do que está em litígio, tudo dirigido à sua capacitação íntima no processo de tomada de decisão e para a adoção de contornos de sua justificação correspondente.

$\mathrm{Na}$ verdade, cremos que a correta liberdade do julgador advém de sua capacidade de captação, compreensão e interação dos fatos, valores, normas e pessoas com outras 
perspectivas que não apenas as normativas.

Deve o magistrado, pois, conjugar tudo o captado, pensado e sentido a respeito do problema identificado com a receptividade social da solução proposta (contexto) e correspondente adaptação do texto à realidade social vivenciada no momento da aplicação.

Para tanto, é necessária a adoção de uma atitude sensível diante da complexidade que é submetida à apreciação, o que não pode ocorrer sem desapego do entendimento originário, literal e clássico das normas, fatos, valores e pessoas, mas com a aproximação humana de ditos elementos encarregados de interpretação da realidade.

Adotamos, nesta perspectiva, concepção intensamente social, profundamente humana, criticamente responsável e ousadamente transcendente no sentido de serem, ou passarem a ser, o Direito e a Justiça, elementos de emancipação.

Descartamos, neste entendimento, as concepções limitadoras do Estado Liberal, ultrapassando-se a mera subsunção racional-formal dos fatos às normas, não mais se conformando com a aplicação sistêmica sem qualquer questionamento a respeito das causas dos fatos ou dos valores, deixando os agentes estatais de favorecer a conservação das diferenças sociais existente.

Como consequência de tal entendimento dá-se o redimensionamento das ideias de certeza e segurança jurídicas, agora entendidas não como estáticas, mas como correspondentes à dimensão ativa concreta dos Direitos e à estabilização plasmática da cidadania dos destinatários.

Superamos, assim, a mera abstração normativa para conjugar-se legitimidade com efetividade social, o que intensifica a função promocional do Direito no estímulo à atuação solidária mais abrangente e uma sociedade mais justa na consolidação da autonomia humanitária e humanizante do Direito, através do diálogo empático como o centro das possibilidades de atuação jurídica e judicial.

É essa a transição paradigmática indicada e desejada na aplicação do Direito, ou seja, considerando as influências existentes e decorrentes dos contatos reais e profundos com a natureza humana e a realidade social, propomos que o julgador absorva intimamente a verificação de sua sensibilidade comunitária no exercício vivo das realidades concretas.

A legitimação daí decorrente apresenta a importância da percepção consciente e sensível de tudo o que nos cerca, para nos orientar na escrita do justo de acordo com os diálogos empáticos, tópicos e poéticos desenvolvidos, como veremos a seguir.

\section{DA TÓPICA E DA POÉTICA COMO LEGITIMAÇÃO E DESCOLONIZAÇÃo}

O protagonismo social e político do sistema judicial e do primado do Direito partem 
da percepção que as sociedades verdadeiramente democráticas não podem funcionar sem um Judiciário eficiente, eficaz, justo e independente, sendo certo que a solução jurídica e judicial deve ser oferecida por meio de julgadores legitimados e imparciais, capazes de aprimorar as convivências, facilitar a realização das potencialidades humanas e dotar a todos da igualdade, liberdade e solidariedades reais.

Assim, propomos a retomada da tópica e da poética no pensamento jurídico e o recobro de seu método na tentativa de resolução dos problemas jurídicos como forma aproximada de trazer o mundo real cada vez mais perto do universo jurídico.

\subsection{A tópica e a seus fundamentos}

Os contatos com os problemas humanos em uma realidade também marcada pelas características pessoais das partes envolvidas indicam a densificação do jurídico na esfera sensível do real e no contato com os fatos social e intimamente vivenciados.

Apartando-nos das meras ficções idealistas de um Direito perfeito em um mundo de formas e aproximando-nos das dores, angústias, pesares, desejos e esperanças concretas, podemos dizer que a tópica, pela recuperação realizada por Theodor Viehweg ${ }^{6}$, volta a representar uma tentativa de fazer o mundo jurídico mais afetivo e pessoal, na busca incessante de fazer justiça.

O termo "tópica" tem matriz na expressão grega topos, correspondente à palavra latina locus e refere-se à ideia de lugar-comum e ponto de vista, além de poder ser entendido como ângulos de visão, níveis de percepção ou mesmo versão aceitável do que é examinado.

As bases dos raciocínios tópicos e argumentativos do pensamento aristotélico foram de fundamental importância para a cultura jurídica ocidental, sendo também adotadas por Cícero e aplicadas pelos próprios juristas romanos, além de terem servido de fundamento para o pensamento jurídico medieval.

O pensamento tópico, característico da Antiguidade Greco-Romana foi retomado por Theodor Viehweg e direcionado à análise da matéria jurídica, aproximando-a dos modernos precedentes. Propôs o autor que o estudo das Ciências Jurídicas incorporasse o processo de aplicação do Direito, superando a mera análise estrutural do ordenamento jurídico e da relação entre suas normas.

${ }^{6}$ VIEHWEG, Theodor. Tópica e jurisprudência: uma contribuição à investigação dos fundamentos jurídico-científicos, tradução da 5. ed. Alemã, Prof ${ }^{a}$. Kelly Susane Aflen da Silva, Porto Alegre: Sergio Antonio Fabris, 2008. 
A tópica, por conseguinte, cuida de opiniões aceitas que estabelecem soluções para problemas, sendo associada ao instrumental dialético dos processos argumentativos, expressando-se como capaz de oferecer soluções para problemas, desde a apresentação e refutação entre teses até se chegar a uma versão aceitável.

Para Theodor Viehweg ${ }^{7}$, o problema envolve "toda questão que aparentemente permite mais de uma resposta e que requer necessariamente um entendimento preliminar, de acordo com o qual toma o aspecto de questão que há que levar a sério e para a qual há que buscar uma resposta como solução".

O raciocínio tópico é, pois, marcadamente utilizado no contexto das situações para as quais não há uma solução ou orientação decisória previamente estabelecida, cabendo o desenvolvimento e eleição de opções plausíveis e a adoção de uma delas para o caso concreto e que possa vir a servir de base para a solução de problemas semelhantes no futuro.

Assim, do acúmulo de tais soluções possíveis e dadas aos problemas forma-se, segundo Theodor Viehweg ${ }^{8}$, um acervo de respostas para problemas, que constitui um sistema.

Sobressai o autor, ainda, a importância de se investigar qual enfoque será destacado no processo de aplicação do direito, a saber, o do sistema ou o do problema.

É que, se o destaque for centrado no sistema, os problemas e suas soluções passam a ser analisados de acordo com o catálogo de deduções aceitos pelo sistema, adotando-se sua padronização. Tal inclinação faz com que as próprias existências das questões sejam percebidas de acordo com referida estandardização, ou seja, só é problema aquilo que o sistema reconhece como tal. Nesta hipótese, caso não corresponda ao já verificado e aceito, a questão não é jurídica, podendo pertencer a outras dimensões.

Em outra vertente, se o problema passa a ser o ponto de referência básico, caso um determinado sistema dedutivo não ofereça uma solução, admite-se a busca em outros sistemas uma forma de resolução.

A tópica parte exatamente deste segundo tipo de abordagem, assumindo como relevante a resolução dos problemas e não o apego a insuficiências sistêmicas.

Raciocinar com base no problema exige uma capacidade de buscar soluções que ao mesmo tempo sejam aceitáveis em termos sistêmicos e correspondam às peculiaridades do caso sob análise, o que exige do intérprete e aplicador muito mais sensibilidade e consciência social.

\footnotetext{
${ }^{7}$ VIEHWEG Theodor, Tópica e Jurisprudência, op. cit., p. 34.

${ }^{8}$ VIEHWEG Theodor, Tópica e Jurisprudência, op. cit., p. 34.
} 
Inexiste incompatibilidade lógica entre o raciocínio tópico e a existência de premissas orientadoras do pensamento, pois agir de acordo com topoi implica uma relação de complementaridade entre a análise específica do problema estudado e a verificação da adequabilidade das premissas.

Assim, longe de qualquer atuação arbitrária, o que se verifica é a construção tópica das premissas desde a análise dos problemas, sendo tais premissas tabuladas e organizadas logicamente, pelo que os sistemas encontram nos próprios problemas sua fonte de geração de premissas, que se alteram e se ampliam na mesma proporção em que surgem problemas ou em que são formuladas soluções renovadas para problemas previamente existentes. No dizer de Theodor Viehweg ${ }^{9}$,"o modo de buscar as premissas influi na índole das deduções e, ao contrário, a índole das conclusões indica a forma de buscar as premissas".

O uso da analogia e os tipos distintos de argumento utilizados em Direito (a símile, a contrario, a maiore ad mines etc.) ${ }^{10}$ têm base tópica ${ }^{11}$ e orientação dialética, sendo certo que a noção de catálogo de topoi, não cria um sistema estanque e sim um conjunto que deve ser dotado de certa flexibilidade, a fim de que se possa adequar a novos problemas. Para tanto, a interpretação constitui um precioso instrumento deste estabelecimento de argumentos e raciocínios coerentes e aceitáveis, possibilitando a superação de premissas antigas sem rupturas traumáticas, na adaptação das máximas vigentes no sistema aos novos problemas da vida real.

Neste sentido, a Hermenêutica Jurídica fornece consideráveis contribuições para a afirmação da tópica no Direito, tendo Theodor Viehweg ${ }^{12}$ defendido a ideia de que o raciocínio tópico não conduz a vinculações absolutas e, ao reconhecer que alguns vínculos são indispensáveis, obtêm-se um mínimo de consenso e previsibilidade, malgrado não lidar com verdades e sim com opiniões majoritariamente aceitas, surgidas em razão de procedimentos argumentativos.

\subsection{Da poética de Giambattista Vico ao processo pluralista.}

Como se sabe, a Poética ${ }^{13}$ é um conjunto de anotações das aulas de Aristóteles sobre poesia e arte, sendo considerado o primeiro escrito que procurou, especificamente, analisar determinadas formas de arte e literatura.

\footnotetext{
${ }^{9}$ VIEHWEG Theodor, Tópica e Jurisprudência, op. cit., p. 40.

${ }^{10}$ VIEHWEG Theodor, Tópica e Jurisprudência, op. cit., p. 40.

${ }^{11}$ VIEHWEG Theodor, Tópica e Jurisprudência, op. cit., p. 40.

12 VIEHWEG Theodor, Tópica e Jurisprudência, op. cit., p. 41.

${ }^{13}$ ARISTÓTELES, Poética, prefacio de Maria Helena da Rocha Pereira, Tradução e notas de Ana Maria Valente, $3^{\mathrm{a}}$ edição, Lisboa: Fundação Caloustre Gulbenkian, 2008.
} 
Podemos dizer, em resumo ${ }^{14}$, que para o estagirita, poesia é uma imitação pela voz, enquanto as artes plásticas imitam pela cor e forma, a dança pelo ritmo, e a poesia lírica, a tragédia e a comédia imitam pelo ritmo, pela linguagem e pela melopéia.

Observemos, contudo, que se a produção da imagem poética (mimema) não se confunde com a experiência objetiva das coisas e ações, tampouco é mera reprodução do ocorrido. É que em sua composição, algo de novo é também introduzido na restauração dos fatos, textos e movimentos, inclinando-se para representar as coisas como poderiam ou deveriam $\operatorname{ser}^{15}$.

Podemos afirmar que Giambattista Vico ${ }^{16}$ resgatou a poética ao defender uma filosofia da imaginação, com o primado da fantasia sobre a razão. Para o autor, a filosofia tópica sobrepõe-se sobre a racional e a poética é aqui entendida como uma forma pura do espírito, sendo a intuição considerada a primeira linguagem do homem e sua forma de conhecimento.

Assim, para o autor, a primeira forma do conhecimento é traduzida pelas formas poéticas, ou seja, pela vida sensitiva e pela vida da fantasia, em processo que se verifica no ser, como um ciclo em espiral a promover novas descobertas.

Para Giambattista Vico, nosso universo é muito mais rico em emotividade e fantasia do que normalmente nos damos conta, sendo certo que o senso comum não é um dado da razão ou do costume, mas é uma disposição natural, enquanto as tradições e as leis não são verdades filosóficas, mas formação consuetudinária e arbitral.

Pretende o autor que as pessoas possam compreender-se reciprocamente e que exista um mundo humano comum participativo e acessível a todo indivíduo. Sua convicção é de que a fantasia, só ela e seus elementos essencialmente humanos, e não a razão absoluta e apriorística, tem a capacidade de aprofundar o conhecimento da natureza humana e, acrescentamos, realizar a justiça.

Verificamos que os processos judiciais possuem, em seu âmago, inúmeros pontos de contato com a poética e com demais formas artísticas, e da mesma maneira não apenas como mera imitação do ocorrido, vez que vivos e reais, mas como integração de versões e composição de uma obra nova.

\footnotetext{
${ }^{14}$ ARISTÓTELES, A Arte poética, tradução de Pietro Nassetti, São Paulo: Martin Claret, 2011, p.12.

15 ARISTÓTELES, Poética- edição bilíngue, tradução, introdução e notas de Paulo Pinheiro, São Paulo: Editora 34, 2015, p.8-9.

${ }^{16}$ VICO, Giambattista, Ciência Nova, título original Principi di Scienza Nuova, tradução de Jorge Vaz de Carvalho, Lisboa: Fundação Calouste Gulbenkian, 2005.
} 
O que nos interessa registrar, ainda, é que os vários conceitos utilizados para descrever como a arte imita a vida acabam por nos fazer perceber que a vida, principalmente a contida nos processos, supera o mais criativo dos autores e, portanto, merece ser sempre acolhida com esmero, sensibilidade artística e acuidade delicada.

Podemos dizer que não apenas o enredo é preponderante na promoção do acontecimento processual trágico, vez que muito se obtém pela construção ou revelação dos personagens durante todo o curso da ação.

Observemos que não é apenas ao final do feito que os agentes se expõem, mas durante toda a, por assim dizer, representação cênica jurídica, é que os personagens vão sendo desvendados através de seus valores, medos, esperanças, utopias e mesmo descrenças.

Mas no curso processo ocorre ainda outro fenômeno. Os personagens são modificados pelo contato com as versões apresentadas e mediante o diálogo empreendido. A rigor, ninguém sai o mesmo de um processo ou de uma audiência, da mesma maneira que assim ocorre após um espetáculo cênico profundo.

Assim, há de ser observada a possibilidade de se desenrolarem novos dramas e ansiedades de acordo como o Direito é percebido e reproduzido, mormente no que diz respeito às possibilidades de modificação da realidade ou das ficções legais pelo próprio Direito concretizado, daí não serem os processos apenas reproduções da vida, mas uma forma de vida.

Os profissionais do Direito não são, no entanto, reais historiadores, vez que é de todo impossível reportar com exatidão, seja por escrito ou oralmente, os fatos ocorridos, bem como inatingível a real percepção das intenções do elenco, mas tão somente seus propósitos imediatos.

Ademais, se os historiadores possuem a missão de revelarem como e porque os fatos ocorreram, os profissionais do Direito também se preocupam com o que deveria ou poderia ter ocorrido ${ }^{17}$, fornecendo hipóteses de desfecho para os dramas ainda em desenvolvimento.

Observemos, ainda, que a capacidade de reconstrução parcial da verdade é sempre limitada pelo tempo razoável da duração do processo, bem como pelas bordas humanas de tal atividade, sendo claro que a captação do ocorrido e os sentidos correspondentes se dão com a influência de pré-leituras da realidade.

Não há dúvida que tragédias são diariamente judicializadas, mas o que nos conforta é que todo processo representa uma possibilidade de reescrita do fim previsto.

\footnotetext{
${ }^{17}$ NUSSBAUM, Martha. Poetic Justice- the literary imagination and public life, Boston - Massachusetts: The Alexander Rosenthal Lectures, Northwestern University Law Scholl, Beacon Press, 1995 e Paisajes Del pensamientola inteligência de las emociones, título original Upheavals of Thought, Barcelona: Editora Paidós, 2008.
} 
Em cada ação, a ventura dos personagens manifesta-se, no dizer de François $\mathrm{Ost}^{18}$, em um palimpsesto, onde a segunda inscrição dá-se por cima da inicial raspada, mas não a encobre totalmente, podendo esta ser vista através da transparência do tempo.

Tal processo de reescrita recebe, queiramos ou não, todas nossas fragilidades, angústias e dúvidas, e em suas linhas restam espremidas nossa alma, nossa loucura, nossos desertos, amores e vida, representando o que nos tornamos, refletindo o que esperamos ser e espelhando o possível sobrevir.

Por entre as linhas do novo texto a ser não apenas lido, mas verdadeiramente encenado, transpiram estranhas criaturas que são os nossos sentimentos e percepções, além da sempre presente possibilidade de equívocos em todos os matizes, tudo ocorrendo em uma escrita ou tragédia conjunta, sendo todos, ao mesmo tempo, responsáveis e influenciados pela escrita e dramatização de tal obra coletiva.

No direito, são os próprios personagens que trabalham em coautoria criativa, seguindo apenas um roteiro básico dos ritos processuais, sem esquecer que, além das cenas externas, desenrolam-se dramas internos, movidos por composições prévias, mas desprovidos de qualquer sina considerada.

São inúmeras as peças que os profissionais do Direito tecem e vivenciam diariamente e todas com fortes doses de emoção, sejam porções de raivas e indignações ou mesmo quinhões de compreensão, tolerância, perdão e, principalmente, compaixão.

A compaixão talvez seja a mais humana das virtudes e abre-se ao outro como amor, sem se deter em ideologia, religião, status social ou diferenças culturais. É ela que anula as indiferenças e implica assumir a paixão do outro, seu sofrimento, padecimento, solidão e dor, na reunião ativa de procedimentos solidários.

E isso sem qualquer reflexão prévia maior, nem argumentação ou discurso, não se questionando se o outro vitimado foi atingido pelas conjunturas econômicas, pela negligência do Estado, pelas sombras da ignorância, por vícios ou por seu destino familiar inicial.

Age-se em direção ao encontro do outro simplesmente por nossa natureza compassiva, no entrelaçamento social inerente à nossa alma. É a pessoa procurando outra e encontrando a si mesmo.

Cremos poder afirmar que tais fenômenos ocorrem diariamente nos tribunais do mundo inteiro, sendo possível, assim, adotar-se um pluralismo jurídico oficial.

\footnotetext{
${ }^{18}$ François Ost esclarece que o raciocínio jurídico acaba por propiciar a presença de um texto num outro texto por vias de citações, compilações e referências. Noutros casos, um texto remeterá para o seu paratexto (esboços, preâmbulos) e ora um texto remete para outro texto (metatexto) que propõe seu estudo crítico (exemplifica a doutrina como um metatexto enxertado na jurisprudência e na legislação). De qualquer forma, em quase todos os casos, os textos jurídicos derivam de textos anteriores. OST, François, O Tempo e o Direito, título original Le Temps du Droit, tradução de Maria Fernanda Oliveira, Lisboa: Instituto Piaget, 2001, p.102.
} 
Propomos, portanto, que ao lado do pluralismo externo, tenhamos também o pluralismo jurídico oficial interno e que seus fundamentos e propósitos sejam o tópicopoético, na esperança de que o esperado desfecho processual se dê pela catarse da compaixão e suas características de cuidado, esmero, sensibilidade, acolhimento e dedicação.

\section{CONCLUSÃO}

A perspectiva da tópica e da poética sugerida apresenta-se como possibilidade de descolonização do futuro, permitindo que o Direito e a Justiça estatal exercitem constantemente suas conversões à democracia solidária através da prevalência do humanismo reinterpretado nas atuações de seus julgadores.

Defendemos que, agindo assim, o Judiciário estatal estará em constante processo de sensibilização ativa e correspondente legitimação social, oferecendo dentro de suas próprias fronteiras, o pluralismo jurídico necessário às demandas do século XXI.

Cremos que para tanto há que se utilizar de dimensões mais transcendentes da ciência, alargando-se os horizontes de percepção para além dos rigores de determinação, certeza e verdade ao acolher-se como métodos legítimos de aspiração evolutiva dos pensamentos, fornecendo hipóteses não apenas lógicas e racionais, mas também propondo maior espaço para a compreensão mais profunda de tudo, com aproximações intuitivas e percepções emocionais.

A perspectiva propõe, pois, a reflexão da problemática da efetivação dos direitos através de uma particular forma de encarar-se a atuação jurisdicional estatal formal, resgatando-se boa dose de idealismo utópico sempre necessário, através da presença e conjugação da tópica e da poética, inaugurando-se a possibilidade do pluralismo jurídico ocorrer internamente e de maneira oficial, sempre socialmente sensível e eticamente responsável.

\section{REFERÊNCIAS}

ARISTÓTELES, Poética, prefacio de Maria Helena da Rocha Pereira, Tradução e notas de Ana Maria Valente, Lisboa: Fundação Caloustre Gulbenkian, $3^{\mathrm{a}}$ edição, 2008.

- A Arte poética, tradução de Pietro Nassetti, São Paulo: Martin Claret, 2011.

- Poética- edição bilíngue, tradução, introdução e notas de Paulo Pinheiro, São Paulo: Editora 34, 2015. 
APPIAH, Kwame Anthony, Mi Cosmopolismo - entrevista com Daniel Gamper Sachse, sem indicação de título original, tradução de Lilia Mosconi, Barcelona: Katz Editores e Centro de Cultura Contemporánea de Barcelona, 2008.

HESPANHA, António Manuel, Cultura Jurídica Européia - síntese de um milênio, , Sintra: Publicações Europa-América, $3^{\text {a }}$ edição, 2003.

NABAIS, José Casalta, Alguns perfis da propriedade colectiva nos países do civil Law. Estudos em Homenagem ao Professor Doutor Rogério Santos. Boletim da Faculdade de Direito da Universidade de Coimbra, Coimbra n. 61, 2001 (p.224-251).

NUSSBAUM, Martha. Poetic Justice- the literary imagination and public life, Boston Massachusetts: The Alexander Rosenthal Lectures, Northwestern University Law Scholl, Beacon Press, 1995.

- Paisajes Del pensamiento- la inteligência de las emociones, título original Upheavals of Thought, Barcelona: Editora Paidós, 2008.

SANTOS, Boaventura de Sousa e TRINDADE, João Carlos (org.), Conflito e Transformação social: uma paisagem das justiças em Moçambique, Vol.I, Porto: Afrontamento, 2003, pp.47-128.

VIEHWEG, Theodor. Tópica e jurisprudência: uma contribuição à investigação dos fundamentos jurídico-científicos, tradução da 5. ed. Alemã, Prof ${ }^{a}$. Kelly Susane Aflen da Silva, Porto Alegre: Sergio Antonio Fabris, 2008

VICO, Giambattista, Ciência Nova, título original Principi di Scienza Nuova, tradução de Jorge Vaz de Carvalho, Lisboa: Fundação Calouste Gulbenkian, 2005.

OST, François, O Tempo e o Direito, título original Le Temps du Droit, tradução de Maria Fernanda Oliveira, Lisboa: Instituto Piaget, 2001. 